\title{
Image Analysis Quantifies Reduction in Sweetpotato Skinning In-jury by Preharvest Canopy Removal
}

\author{
D.R. La Bonte' and M.E. Wright ${ }^{2}$ \\ Department of Horticulture, Louisiana State University Agricultural Center, \\ Louisiana Agricultural Experiment Station, Baton Rouge, LA 70803-2120
}

Additional index words. Ipomoea batatas, mechanical harvesting, skinning damage

The objective of this study was to develop a rapid, economical method to quantify sweetpotato root surface area to aid in selecting skinning-resistant sweetpotatoes and to use in improving the design of harvesters to reduce skinning. Here we report a technique using heat shrink wraps of sweetpotato storage roots and image analysis. This technique is applied in a study of preharvest canopy removal as a means of reducing skinning of mechanically dug sweetpotato storage roots.

Sweetpotato storage roots were enveloped in clear $14-\mu \mathrm{m}$-thick heat shrink wrap and placed on a conveyor belt entering a 119C commercial shrink-wrap oven (Sergeant flexible packing machinery; Allied Automation, Dallas) for $24 \mathrm{sec}$. The wrap then was removed, cut to lie flat, spray-painted black, and imaged onto a picture monitor (model PM930; Ikegami Tsushinki Co., Utsunomiya City, Japan) using a television camera (Ikegami model ITC-410). An area meter (model RS232C; Delta T Devices, Cambridge, England) was used to measure total surface area.

A two-step imaging process was used to determine skinned surface area on storage roots. Before removing the shrink wrap from a root, the skinned areas, exclusive of areas damaged by insects and disease, were covered with opaque paint, the wrap was removed, and the area of the painted spots was determined by imaging. Next, the entire shrink-wrap surface was spray-painted black and the total surface area determined.

\footnotetext{
Received for publication 2 Apr. 1993. Accepted for publication 3 Aug. 1993. Approved for publication bythedirectoroftheLouisiana Agricultural Experiment Station as manuscript no. 93-28-7045. Supported by state and matching funds allocated to the Louisiana State Univ. Agricultural Center and the Louisiana Sweet Potato Advertising and DevelopmentCommission. We gratefully acknowledge the laboratory assistance of F.A. Buffone and E.R. Olsen. The cost of publishing this paper was defrayedinpartbythe payment of page charges. Under postal regulations, this paper therefore must be herebymarked advertisement solelyto indicate this fact.

${ }^{1}$ Assistant Professor. To whom reprint requests should be addressed.

${ }^{2}$ Professor,BiologicalandAgriculturalEngineering Dept.
}

The precision of determining total surface area by this technique was tested by repeatedly wrapping three U.S. No. 1 roots eight times. Mean total measured surface area ranged from $185 \mathrm{~cm}^{2}$ for the smallest root to $281 \mathrm{~cm}^{2}$ for the largest root. Standard deviation was $<2 \mathrm{~cm}^{2}$ for each of the three roots, indicating high repeatability.

Image analysis techniques have shown the close resemblance of the sweetpotato shape to the ellipsoid (Wright et. al., 1986). To test the accuracy of the shrink-wrap method, nine plastic ellipsoids of various sizes were turned on a lathe and each was shrink-wrapped 10 times. The dimensions of the ellipsoids were all within the maximum and minimum lengths and widths allowed for U.S. No. 1 grade sweetpotatoes. Surface areas determinedly calculation ranged from 93 to $530 \mathrm{~cm}$ '. The average for the 10 measurements for each shape was compared to each calculated surface area. The range of differences was $-2.5 \%$ to $-9.0 \%$, averaging -5.270 . The negative values in all cases indicate a slight problem in flattening the shrink wrap after it was removed from the sweetpotato.

We used this technique to determine whether preharvest canopy removal reduces the severity of root skinning of mechanically harvested sweetpotatoes. 'Beauregard' and 'Jewel' sweetpotatoes were transplanted on 15, 22, and 29 May 1992 at the Hill farm, Baton Rouge, La., and on 29 May, 6 June, and 17 June at the Sweet Potato Research Station, Chase, La. Twenty transplants per plot were placed $0.3 \mathrm{~m}$ apart within rows and 1.2 or 1.0 $\mathrm{m}$ between rows at Baton Rouge and Chase, respectively. These plantings were harvested in sequential order after 131, 132, and 133 days at Baton Rouge and 103,105, and 99 days at Chase. The soil at Chase was a Gilbert silt loam (fine-silty, mixed, thermic, Typic Glossaqualf). The soil at Baton Rouge was a Loring silt loam (fine-silty, mixed, thermic, Typic Fragiudalf). Treatments consisted of removing the canopy at ground level $0,4,8$, and 10 days preharvest, using either a rotary or flail mower. All roots were mechanically harvested with a one-row chain-belt digger. Roots traveled $170 \mathrm{~cm}$ on the chain and then dropped $60 \mathrm{~cm}$ to the soil surface. They were collected subsequently by hand and dropped $40 \mathrm{~cm}$ into wooden crates. This procedure simulated typi- cal treatment of roots during harvest. Roots then were cured for 5 days at 29C and $85 \%$ relative humidity before being washed with a commercial vegetable washer. No fresh abrasions were noted after washing. Experimental units consisting of four U.S. No. 1 grade cured and washed sweetpotatoes (5.1 to $8.9 \mathrm{~cm}$ in diameter and 7.6 to $22.9 \mathrm{~cm}$ in length) were selected randomly from each field plot to evaluate skinning. Skinned surface area was determined by the two-step shrink-wrap and imaging method. Results were reported as a percentage of the total area skinned (damaged area/total area $\times 100$ ).

The design was a split plot in a randomized complete block design with the four mowing treatments as the main plot factor and the two cultivars as the subplots in four replications; data were tested by analyses of variance, and trends in canopy removal were determined using linear regression (SAS, 1986). Effects of location, date, treatment, and cultivars were all considered random. Data were combined for the two cultivars because no significant cultivar $\times$ treatment interaction $(P<0.05)$ was shown.

Preharvest canopy removal linearly reduced skinning damage in 'Beauregard' and 'Jewel' combined $(P<0.001)$. The effect of the time of canopy removal on skinning damage is described by the equation $\mathrm{y}=-0.38 \mathrm{x}+5.28$, where $\mathrm{y}=$ percent skinning damage and $\mathrm{x}=$ days mowed preharvest. The $R^{2}$ value was 0.50 , and the sample size was 720 . Overall skinning damage was reduced by $62 \%$ when the canopy was mowed 10 days preharvest, $53 \%$ when mowed 8 days preharvest, and $26 \%$ at 4 days when compared to 0 days preharvest. In previous research, no further significant reduction in skinning was observed when the canopy was mowed 15 days preharvest (La Bonte and St. Amand, 1989). Roots also began to sprout after 15 days; thus, this treatment was not included in the current study.

Our results confirm those of Austin and Graves (1970), who used various mechanical and chemical defoliants to reduce sweetpotato harvest injury by preharvest canopy removal. Their study differed from ours in that roots were plowed out at harvest, injured artificially by handling, and rated subjectively on a visual basis. Our results extend theirs by demonstrating that early canopy removal has the potential for reducing skinning of sweetpotato roots harvested with mechanical diggers.

\section{Literature Cited}

Austin,M.E. and B. Graves. 1970. Preharvest treatments on skinning of sweet potato roots. J. Amer. Soc. Hort. Sci. 95:754-757.

La Bonte, D.R. and P.C. St. Amand. 1989. Effect of early vine removal on skinning of sweetpotato. ASHS 1989 Annu. Mtg., Tulsa, Olda., Prog. \& Abstr. p. 62.

SAS. 1986. SAS systems for linear models. SAS Institute, Cary, N.C.

Wright, M. E., J.H. Tappan, and F.E. Sistler. 1986. The size and shape of typical sweet potatoes. Trans. Amer. Soc. Agr. Eng. 29:678-582. 